$\xi_{p}$

\title{
Development of Design "Simulator for Active Musical Therapy" by Taking into Account the Principles of Universal Design
}

\author{
N.E. Milchakova, K.A. Nazarova \\ MIREA - Russian Technological University, Moscow, Russia
}

\begin{abstract}
The present paper describes the process of developing and creating design of the "Simulator for active music therapy" with adaptation for blind people. Formation and improvement of the subject-spatial environment for all social groups of the population, as well as people with disabilities (HIA) is an important task of modern society. Research in the psycho-emotional state of a person allows using various methods, such as musical influence, to provide improvements and emotional regulation of a person with a disability.
\end{abstract}

Keywords: simulator, music Design, Vibration

\section{Introduction}

The purpose of this paper is to provide an architectural design and a scientific approach based on the principles of sustainable architecture in order to offer a residential building model in Shahrsand-dagh, so that with practical solutions for the use of inactive solar energy, the field for the use of clean and renewable energy Provided. To this end, the proposed model was first designed based on climate design criteria and standards. In order to avoid sunlight exposure to the building in the summer, the shadows according to scientific principles were calculated and designed for the south side windows. Modeling and simulation model was used to validate and simulate the power consumption of the model building, using Ecottek and Plus Energy software. In order to ensure the efficiency of the proposed model, the simulation was initiated by taking into account the shading for the south side windows, the thermal insulation of the outer walls and the installation of double glazed windows. Then simulated and analyzed the same unshielded, thermal insulation pattern with respect to single-wall windows. At the end, the results were compared with each other. The pattern that energy conservation measures have not been considered for, requires three times more energy for cooling and heating.

The Simulator for Active Music Therapy (TAMT) is a new correctional tool used to form psycho-functional comfort $[1,2,3]$.

\section{Features of development of tamt design}

At the beginning of the development of any design, it is necessary to become familiar with analogues that already exist on the market. Controllers and mixing consoles for DJing were used as analogues for TAMT.

Consider the design elements corresponding to the style of DJ equipment, which can be used to create TAMT:

1) rectangular buttons - pads arranged in rows;

2) neon colors of the pads, illuminated when pressed;

3) black color control panel;
4) sliders with indicated levels - faders;

5) knobs that switch music tracks or volume;

6) drawings and short captions guiding the user;

7) the location on the side panels of additional buttons, inputs and outputs for various devices (computer, speakers);

8) rectangular shape of the device.

The main objectives of TAMT design are usability of the device by people with disabilities, as well as people whose main goal is not to create music, but to improve their mental health. Consequently, the interface should be as simplified as possible, since the device is intended for people without training and special skills [3]. For comfortable use of the device by visually impaired or blind people, signatures will be duplicated in Braille.

A sketch of the control panel was made in a vector program in order to determine the presence of basic elements and their composition before 3D modeling.

One of the main problems in the design of the patch panel is the application of Braille. Braille duplicates the black (regular) font. Words in Braille occupy a large space, which radically complicated the task of compositional arrangement of elements in the style of DJ equipment. The standard font was chosen from standard sizes for Braille according to GOST R 56832-2015. Its standard dimensions are shown in Figure 2.
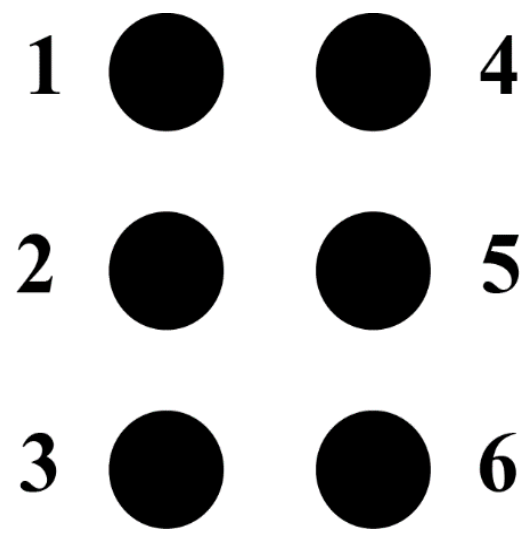

Fig. 1: The main coordinate grid of Braille. 


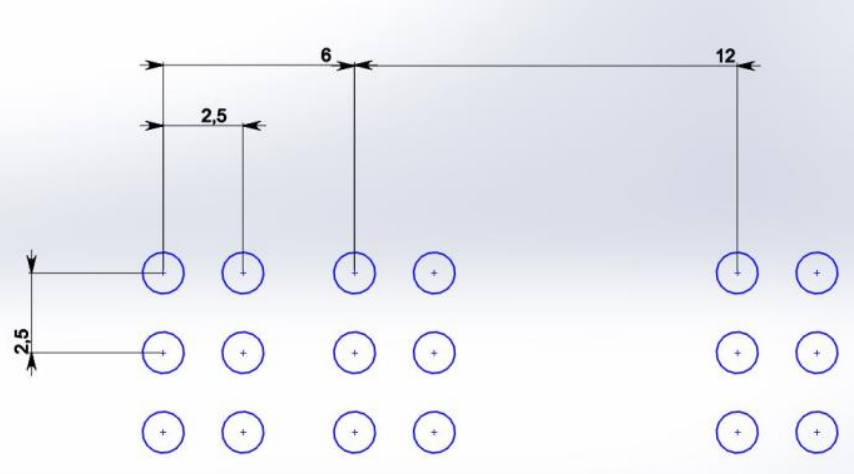

Fig. 2: Diagram of the size of braille [6].

In the process of editing the sketch of the top panel, the controls (buttons, faders, rotary knobs) and additional design elements (labels, volume levels and speed scales) of TAMT were logically grouped into a certain spatial structure, taking into account:

1) the sequence of their use;

2) time of use;

3) the importance of the governing body;

4) ergonomic arrangement of tools;

5) compositional balance of the device design elements;

6) stylistic unity;

7) principles of universal design.

When creating an aesthetically expressive appearance of the panel, it is necessary to compile interconnected design elements with functional groups in the corresponding section of the panel, ensuring the greatest coincidence of centers along one conventional axial line (Fig. 3).

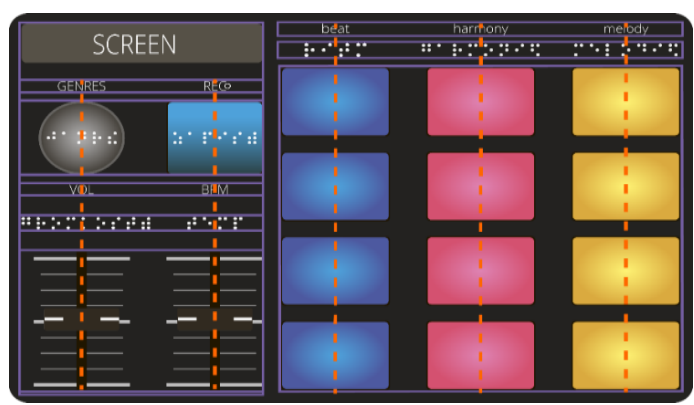

Fig. 3: The layout of the design elements on the control panel.

The final stage of work on the simulated scene is visualization. Figure 10 shows the result of the imaging device.

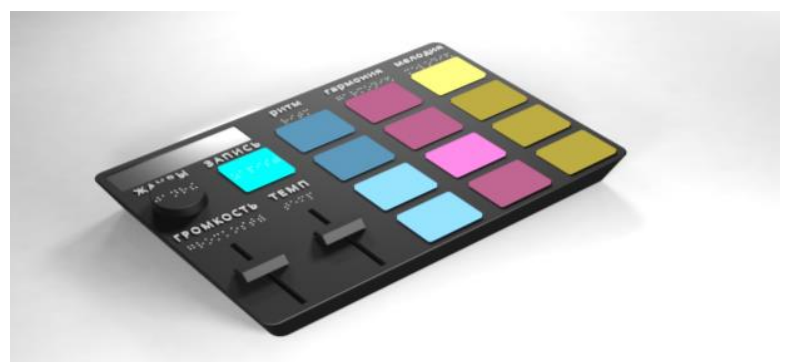

Fig. 4: Visualization of the 3D model of the device

\section{Development of the tamt mobile application design}

As a supplement, the design of the mobile application interface based on the TAMT methodology was developed. The need to create a mobile application for the correction of the psychofunctional state of a person is due to the fact that the mobile phone has become an integral part of modern life.

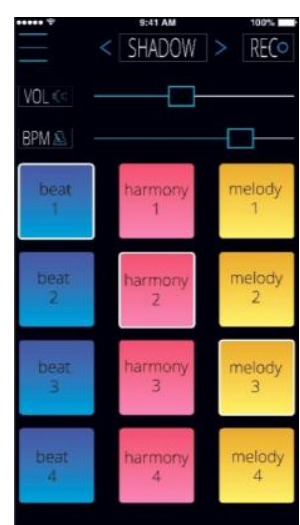

a)

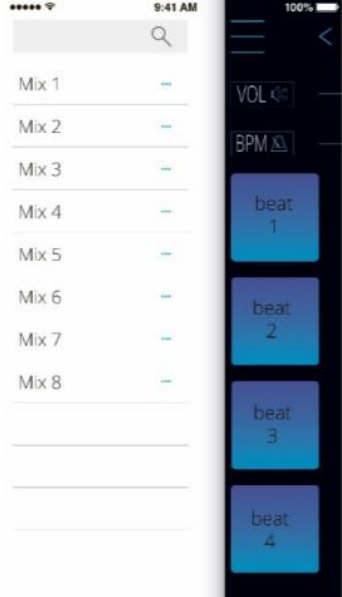

b)
Fig. 5: Type of design of TAMT mobile application, a) - main screen, b) screen with playlist.

Design elements that are trendy at the moment were used: blurred and diffuse backgrounds - gradient buttons with captions, hidden navigation - go to the playlist and track settings, Card Design (card or tile design) - buttons that simulate the pads on the controllers.

\section{Conclusion}

Thus, the design concept of the "Simulator for active music therapy" was developed taking into account the principles of universality, and was adapted for blind and visually impaired people with a functional and intuitive interface to correct human psycho-functional state.

\section{References}

[1] Nazarova K.A., Sapozhnikov M.S., Milchakova N.E. Development and professional development of the human rights law on the special edition of the law. Special Edition p. 1345-1350.

[2] Nazarova K.A. Psychoacoustic Design // Association of Researchers "Siberian Academic Book" (Novosibirsk). - 2014. Vol. 37. - pp. 82-90. [Electronic resource]. - Access mode: https://sibac.info/conf/innovation/xxxvii/39307 (access date 04/05/2018)

[3] Sokolova M.L. Modern problems of the direction "Technology of artistic processing of materials" // Russian technological journal. 2017. - Vol. 5, No. 1 (15) - p. 50-56.

[4] Nazarova K.A., Miroshnik E.V., Chaynova L.D. Psychological development of musical means to optimize the functional state of a person // PSYCHOLOGICAL JOURNAL. - 2016. - Vol. 37 (2). Pp. 105-111. [Electronic resource]. - Access mode: https://elibrary.ru/item.asp?id=26002063 (the date of circulation 01.05.2018).

[5] Online store of musical instruments [Electronic resource]. - Access mode: https://www.gear4music.es/en/PA-DJ-and-Lighting/NativeInstruments-Traktor-Kontrol-F1-DJ-Controller/JA2 (the date of access 04.05.2018).

[6] Online store for musicians [Electronic resource]. - Access mode: https://www.kombik.com/catalog/view/reloop-neon/ (access date 01/05/2018)

[7] GOST R 56832-2015 Braille. Requirements and dimensions [Electronic resource]. - Access mode: http://internetlaw.ru/gosts/gost/61295/ (request date 03/05/2018).

[8] National Aviation University. Designing controls. // StudFiles Student file archive. [Electronic resource]. - Access mode: https://studfiles.net/preview/5376818/page:11/( address of 05/02/2018)

[9] Allfordj Music Store. [Electronic resource]. - Access mode: https://www.allfordj.ru/news/Flagmanskiy_kontroller_ot_Native_In struments_Traktor_Kontrol_S8_segodnya_poyavilsya_v_Rossii_/ (appeal date 04.05.2018) 